\title{
Evaluation Residual Moisture in Lithium-Ion Battery Electrodes and Its Effect on Electrode Performance
}

\author{
Jianlin Li, ${ }^{1 *}$ Claus Daniel, ${ }^{1,2}$ Seong Jin An, ${ }^{1,2}$ and David Wood ${ }^{1,2}$ \\ ${ }^{1}$ Energy and Transportation Science Division, Oak Ridge National Laboratory, TN 37831, USA \\ ${ }^{2}$ Bredesen Center for Interdisciplinary Research and Graduate Education, University of \\ Tennessee, Knoxville, TN 37996, U.S.A. \\ *Corresponding author: 1ij4@ornl.gov
}

Notice: This manuscript has been authored by UT-Battelle, LLC under Contract No. DEAC05-00OR22725 with the U.S. Department of Energy. The United States Government retains and the publisher, by accepting the article for publication, acknowledges that the United States Government retains a non-exclusive, paid-up, irrevocable, world-wide license to publish or reproduce the published form of this manuscript, or allow others to do so, for United States Government purposes. The Department of Energy will provide public access to these results of federally sponsored research in accordance with the DOE Public Access Plan (http://energy.gov/downloads/doe-public-access-plan).

\begin{abstract}
Removing residual moisture in lithium-ion battery electrodes is essential for desired electrochemical performance. In this manuscript, the residual moisture in $\mathrm{LiNi}_{0.5} \mathrm{Mn}_{0.3} \mathrm{Co}_{0.2} \mathrm{O}_{2}$ cathodes produced by conventional solvent-based and aqueous processing is characterized and compared. The electrochemical performance has also been investigated for various residual moisture contents. It has been demonstrated that the residual moisture lowers the first cycle coulombic efficiency, but its effect on short term cycle life is insignificant.
\end{abstract}

\section{INTRODUCTION}

Polyvinylidene fluoride (PVDF) and N-methyl-pyrrolidone (NMP) are the typical binder and solvent for lithium-ion electrode slurry preparation ${ }^{1}$. However, NMP is known for its toxicity and high cost, and it must be recycled with significant capital $\operatorname{cost}^{2}$. There is growing interest in switching manufacturing composite electrodes from solvent-based processing to aqueous processing for economic and environmental benefits ${ }^{3-9}$. While aqueous processing is relatively mature for graphite anodes, it still remains a challenge for cathode materials due to the complexity of handling the cathode oxide slurry in water environment ${ }^{2}$. Recently, great efforts have been made to several cathode materials such as $\mathrm{LiFePO}_{4}{ }^{10,11}, \mathrm{LiCoO}_{2}{ }^{12,13}, \mathrm{LiNi}_{\mathrm{x}} \mathrm{Mn}_{\mathrm{y}} \mathrm{Co}_{1-\mathrm{x} \text { - }}$ $\mathrm{y}_{2} \mathrm{O}_{2}{ }^{4,9}$, and $\mathrm{LiMnO}_{2}-\mathrm{LiNi}_{\mathrm{x}} \mathrm{Mn}_{\mathrm{y}} \mathrm{Co}_{1-\mathrm{x}-\mathrm{y}} \mathrm{O}_{2}{ }^{8,14}$. To enable aqueous processing for composite cathodes, one of the steps is to replace PVDF with a water soluble binder, which must be electrochemically stable in a wide voltage range $\left(0 \sim 5 \mathrm{~V} \mathrm{vs.} \mathrm{Li}_{/} \mathrm{Li}^{+}\right)$, be chemically compatible with other cell components, and pose sufficient cohesion strength for electrode constituents and adhesion strength between electrode and current collector. A variety of binders have been explored and promising results have been demonstrated, including carboxymethyl cellulose (CMC) and styrene butadiene rubber (SBR), ${ }^{4,15}$ water-based fluorine-acrylic copolymer, ${ }^{6}$ polyacrylate (PAA) $)^{16}$, polyurethane ${ }^{17}$, and xanthan gum ${ }^{10}$. Another area of focus has been in 
improving dispersion quality of the aqueous slurry, which affects homogeneity of the electrode constituent distribution and, consequently, electrode performance ${ }^{7}$. The active material and carbon black tend to agglomerate more readily in aqueous suspensions due the high polarity of water and strong interactions between particles. One strategy to mitigate the particle agglomeration issue is adding a dispersant to the suspension. Dispersants, such as polyacrylic acid $^{12}$, poly(4-styrene sulfonic acid) ${ }^{18}$, Triton X-100 19 , and polyethyleneimine ${ }^{20}$ have been utilized to minimize particle agglomeration in aqueous suspensions and improve electrode performance. Yet another problem with aqueous slurries is that the surface tension is higher than the NMP-based ones due to the higher surface tension of water over NMP. This situation can lead to poor suspension wetting on the current collector $^{21}$. To achieve good wetting, it is preferred to have the surface tension of suspension be equal to or lower than the surface energy of the current collector substrate. This problem can be solved by either increasing the surface energy of current collector or reducing the surface tension of suspension. It has been demonstrated that wetting improvement of aqueous $\mathrm{LiFePO}_{4}$ suspensions was enabled via corona treatment of the $\mathrm{Al}$ foil ${ }^{21}$. Appling a coating to the current collector, such as a thin carbon coating, has also been shown to improve suspension wetting and inhibited $\mathrm{Al}$ foil corrosion ${ }^{5}$.

Since water is detrimental to battery performance, another area of concern for aqueous processing is the effect of residual water (moisture) on active material and electrode performance. So far, most efforts have been applied to investigating the stability of active materials in a liquid water environment ${ }^{22,23}$. However, the residual moisture after secondary drying also plays an important role in electrode performance, which is usually overlooked. Given that water soluble binders are typically more hydrophilic than PVDF, the electrodes via aqueous processing have higher moisture uptake. The following questions will inevitably arise:

1) What is the residual moisture in aqueous processed electrodes after baseline secondary drying?

2) How does the residual moisture in electrodes via aqueous processing compare to NMP-based processing?

3) Is a special secondary drying protocol needed to reduce the residual moisture to an acceptable level?

4) What is the residual moisture effect on electrochemical performance?

This work addresses these questions by comparing results from $\mathrm{LiNi}_{0.5} \mathrm{Mn}_{0.3} \mathrm{Co}_{0.2} \mathrm{O}_{2}$ (NMC532) cathodes from both aqueous and conventional NMP-based processing.

\section{EXPERIMENT}

As received NMC532 powder $\left(\mathrm{D}_{50}: 11 \mu \mathrm{m}\right.$; BET: $0.3 \mathrm{~m}^{2} / \mathrm{g}$ ), Denka carbon black (powder grade), carboxymethyl cellulose (Sigma Aldrich, $\mathrm{M}_{\mathrm{w}}=250,000 \mathrm{~g} / \mathrm{mol}$; DS=0.9), modified PVDF latex (Solvay Solef ${ }^{\circledR}$ XPH-859), PVDF (Solvay Solef ${ }^{\circledR} 5130$ ), were used in preparing NMC 532 suspensions. Deionized water and NMP were used as the solvents for aqueous and NMP-based suspension, respectively. A planetary mixer (Ross, PDM $1 / 2$ ) was used for suspension mixing. The NMP-based NMC532 suspension was prepared by dispersing NMC532 in PVDF/NMP solution for $20 \mathrm{~min}$ at 2500 and 25 RPM displacing and planetary mixing speeds, respectively. Then the desired amount of carbon black was added to the resulting suspension and mixed at the 
same speed for another $20 \mathrm{~min}$. Extra NMP was added in the last step for viscosity control. The suspension was mixed at 600 and 25 RPM displacing and planetary mixing speed, respectively, and degassed at 20 in $\mathrm{Hg}$ vacuum. The aqueous NMC532 suspension was prepared similarly except that NMC532 was dispersed in CMC/water solution in the first step and the PVDF latex was added in the last step. The NMC532 cathodes consisted of $90 \mathrm{wt} \%$ NMC532 and $5 \mathrm{wt} \%$ carbon black. The binders were $5 \mathrm{wt} \%$ PVDF for the NMP-based slurries and $1 \mathrm{wt} \% \mathrm{CMC}$ and $4 \mathrm{wt} \% \mathrm{PVDF}$ latex for the aqueous slurries. Both cathodes were coated using a pilot-scale slot-die coater (Frontier Industrial Technology) and were not calendered ( $\sim 50 \%$ porosity after slot-die coating). The areal loading of all NMC532 cathodes was $11.5 \mathrm{mg} / \mathrm{cm}^{2}$. Morphology of the electrodes was characterized by scanning electronic microscopy (SEM, Hitachi TM3030).

Secondary drying of the NMC532 cathodes was carried out in a vacuum furnace (maintaining $30 \mathrm{in} \mathrm{Hg}$ vacuum) at various temperatures ranging from 80 to $120^{\circ} \mathrm{C}$ for 2 hours. The residual moisture in the electrodes was characterized by a Karl Fisher coulometer (C20) at $200^{\circ} \mathrm{C}$ inside a dry room (dew point $=-54^{\circ} \mathrm{C}, \mathrm{RH}<0.1 \%$ ). Before secondary drying, all cathodes were placed outside the dry room over night for saturation at ambient dew point $\left(\sim 15-20^{\circ} \mathrm{C}\right.$ in $20-22^{\circ} \mathrm{C}$ air temperature), which ensured they had the same moisture content.

Half coin cells were assembled inside an argon filled glove box with NMC532 cathodes dried using various conditions and Li metal counter electrodes, respectively. One layer of Celgard 2325 was used as the separator, and the electrolyte was $1.2 \mathrm{M} \mathrm{LiPF}_{6}$ in ethylene carbonate: diethyl carbonate (3/7 wt fraction, BASF). The cells, which were built in triplicate, were cycled between 2.5 and $4.2 \mathrm{~V}$ vs $\mathrm{Li} / \mathrm{Li}^{+}$via VSP potentiostats (Biologic) at $25^{\circ} \mathrm{C}$. They were charged at constant current at $0.2 \mathrm{C}$ to $4.2 \mathrm{~V}$ followed by constant voltage charging until the current dropped to $0.05 \mathrm{C}$. The cells were discharged at constant current until the voltage reached $2.5 \mathrm{~V}$. The C-rate was calculated based on $1 \mathrm{C}=160 \mathrm{~mA} / \mathrm{g}$.

\section{DISCUSSION}

\section{Morphology of NMC532 cathodes}

The morphology of the different NMC532 cathodes was found to be similar as shown in Figure 1, where NMC532 particles are surrounded by a carbon-black network. More small particles were observed in the aqueous processed cathode, which indicates that the NMC532 secondary particles de-agglomerated better in the water suspension.

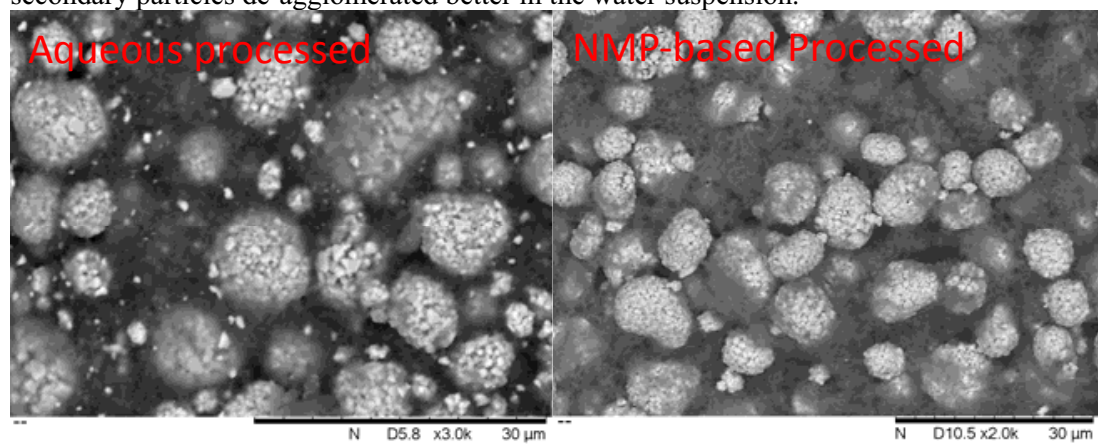

Figure 1. SEM images of the NMC532 cathodes. 


\section{$\underline{\text { Residual Moisture in NMC532 cathodes }}$}

Residual moisture in the aqueous processed NMC532 cathodes was characterized before and after secondary drying, and the results are shown in Figure 1a The aqueous processed NMC532 had 625 ppm of water when saturated with ambient humidity, and this level was defined as the initial moisture content for all aqueous processed cathodes prior to secondary drying. The residual moisture level dropped down to $242 \mathrm{ppm}$ after secondary drying at $80^{\circ} \mathrm{C}$ for $2 \mathrm{~h}$, and it continued decreasing with increasing drying temperature reaching $47 \mathrm{ppm}$ when dried at $120^{\circ} \mathrm{C}$. For comparison, residual moisture in conventional NMP-based processed NMC532 cathodes (referred to as the control samples hereafter) was also evaluated and found to be 200 ppm of water when saturated to ambient humidity (about 1/3 the level of aqueous processed cathodes). For a baseline secondary drying process at $100^{\circ} \mathrm{C}$ for $2 \mathrm{~h}$, the residual moisture went down to $87 \mathrm{ppm}$ in the control samples compared to the $160 \mathrm{ppm}$ for the aqueous processed cathodes. To get to this residual moisture levels in the aqueous processed cathodes, it was found that the temperature needed to be between $110-120^{\circ} \mathrm{C}$, which could lead to extra energy consumption during secondary drying. While it is challenging to get rid of all the residual moisture in either case, the majority of the adsorbed water can be readily removed for the aqueous processed cathodes when they are dried at $100^{\circ} \mathrm{C}$. Figure $1 \mathrm{~b}$ shows the normalized residual moisture in the NMC532 cathodes at various secondary drying conditions, which is defined as the residual moisture after secondary drying divided by the residual moisture saturated with ambient humidity. The normalized residual moisture after drying at $100^{\circ} \mathrm{C}$ was $25.6 \%$ for the aqueous processed cathodes and $43.5 \%$ for the NMP-based ones, indicating $74.4 \%$ and $56.5 \%$ of the initial adsorbed water was respectively removed. When increasing the secondary drying temperature to $120^{\circ} \mathrm{C}, 92.5 \%$ of saturated moisture can be removed resulting in $47 \mathrm{ppm}$ residual moisture in the aqueous processed cathodes.

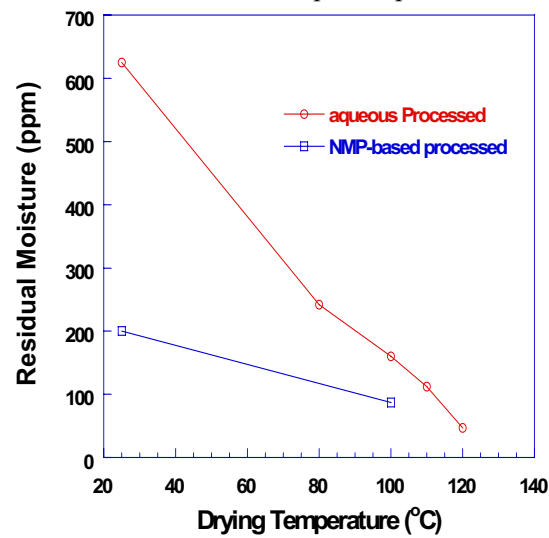

(a)

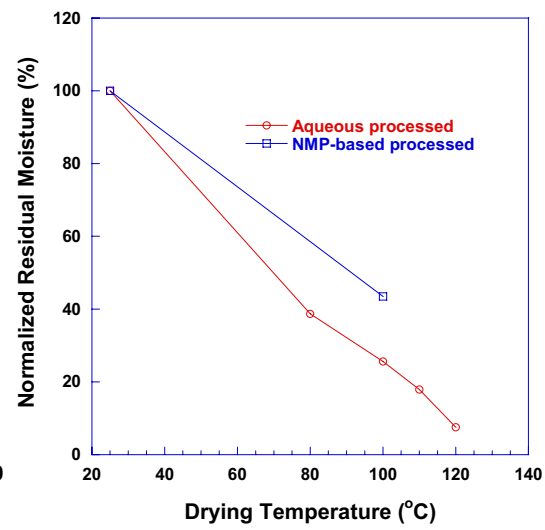

(b)

Figure 2. Residual moisture in NMC532 cathodes as a function of secondary drying temperature a) residual moisture and b) normalized residual moisture. 


\section{Electrode performance versus residual moisture}

The coulombic efficiency of the NMC532 cathodes from the first cycle is compared in Figure 3, which was found to generally increase with increasing drying temperature. Residual water could be decomposed during the charging step, resulting in lower efficiency. The control samples dried at $100^{\circ} \mathrm{C}$ showed the highest coulombic efficiency at $84.2 \%$, but this difference was observed to be small when taking the error bars into account.

The electrochemical performance is shown in Figure 4, which is based on the average capacity from three cells for each condition. Capacity was normalized to the mass of NMC532 active material. All half coin cells went through rate performance testing from $0.2 \mathrm{C}$ up to $5 \mathrm{C}$ followed by 100 cycles at $0.2 \mathrm{C} /-0.2 \mathrm{C}$. The aqueous processed NMC532 cathodes demonstrated comparable rate performance to the control samples and the one dried at $120^{\circ} \mathrm{C}$ even was even better. The slightly superior rate performance from the samples dried at $120^{\circ} \mathrm{C}$ is possibly attributed to the different solid electrolyte interface (SEI) from the water soluble binders and PVDF. The SEI from the water soluble binders could be more conductive, which is beneficial to high rate performance but the improvement is not significant at low rate. After the rate performance test, the capacity at $0.2 \mathrm{C} /-0.2 \mathrm{C}$ recovered well for all cells.

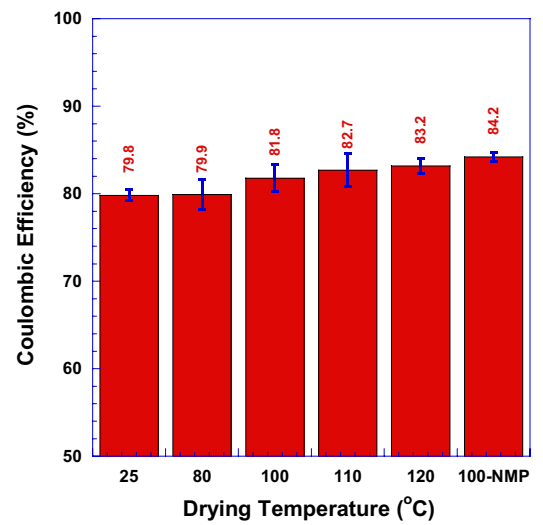

Figure 3. First cycle coulomb efficiency of NMC532 half cells.

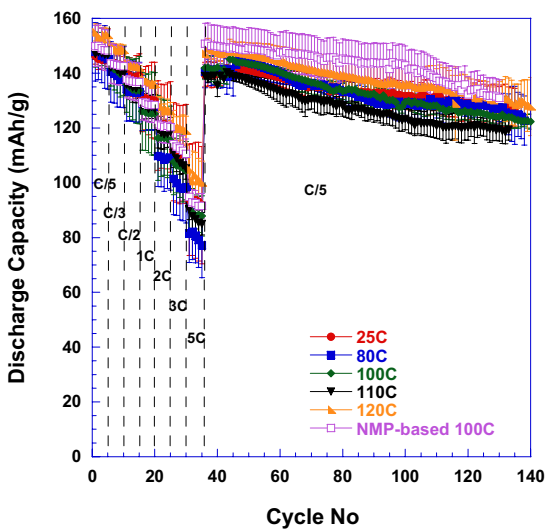

Figure 4. Electrochemical performance of NMC532 half cells.

During the 100 -cycle testing, the average capacity obeyed the following trend: $100^{\circ} \mathrm{C}$ (control) $>$ $120^{\circ} \mathrm{C}>100^{\circ} \mathrm{C} \approx 80^{\circ} \mathrm{C} \approx 25^{\circ} \mathrm{C}>110^{\circ} \mathrm{C}$. Generally, one could make the observation that lower residual moisture favors better capacity magnitude and similar capacity fade. However, when considering the error bars, the one dried at $120^{\circ} \mathrm{C}$ basically demonstrated similar cyclability as the control $\left(100^{\circ} \mathrm{C}\right)$ and the capacity was identical after 100 cycles. It is noted though, large cellto-cell variation common in half coin cell testing with multiple cells of the same type make this observation questionable. There are many factors which affect the electrochemical performance in a half coin cells including electrode area, electrolyte amount, and test protocol ${ }^{24}$. Given that the electrode area is so small for working electrodes in half coin cells, a small defect in the working electrode could lead to substantial variation in performance, and this variation could be larger than that from the residual moisture differences. A second reason is that the residual 
moisture effect may not be significant enough to be observed in a short-term cyclability test. Daniel et al. investigated the effect of the drying protocol for $\mathrm{LiFePO}_{4}$ cathodes assembled into full pouch cells with graphite anodes and reported that electrodes with residual moisture content above $500 \mathrm{ppm}$ showed much faster capacity degradation ${ }^{25}$. However, this increased capacity fading didn't arise until 400 cycles, which is too many cycles for reliable coin cell data. Test results from coin cells, especially half coin cells, are suspect after such long term cycling due to the reaction between lithium and electrolyte, the quality of coin cell parts, etc. This work will be extended by carrying out a similar study in large format (1.5-Ah) pouch cells, which have better control in cell to cell variation, and cycling them to 1000 cycles.

\section{CONCLUSIONS}

Residual moisture in both aqueous and NMP processed $\mathrm{LiNi}_{0.5} \mathrm{Mn}_{0.3} \mathrm{Co}_{0.2} \mathrm{O}_{2}$ cathodes was characterized. While the aqueous processed cathodes showed higher adsorbed water uptake, the residual moisture can be reduced to a similar level as the NMP processed cathodes with a routine secondary drying protocol. $92.5 \%$ of saturated moisture at ambient dew point was removed in aqueous processed samples with a secondary drying protocol at $120^{\circ} \mathrm{C}$. Lower residual moisture content favored coulumbic efficiency in the first cycle. The aqueous processed samples demonstrated comparable rate performance to the control. No significant difference was found in capacity magnitude or fading between the control and the aqueous processed cathodes dried at $120^{\circ} \mathrm{C}$. However, future work is needed with large format pouch cells to minimize the cell to cell variation and extend cycling to 1000 cycles, which allows us to better distinguish the residual moisture effect on electrochemical performance.

\section{ACKNOWLEDGMENTS}

This research at Oak Ridge National Laboratory, managed by UT Battelle, LLC, for the U.S. Department of Energy (DOE) under contract DE-AC05-00OR22725, was sponsored by the Office of Energy Efficiency and Renewable Energy for the Vehicle Technologies Office's Applied Battery Research Program (Program Managers: Peter Faguy and David Howell).

\section{REFERENCES}

(1) Li, J.; Daniel, C.; Wood, D. Journal of Power Sources 2011, 196, 2452.

(2) Wood III, D. L.; Li, J.; Daniel, C. Journal of Power Sources 2015, 275, 234.

(3) Lim, S.; Kim, S.; Ahn, K. H.; Lee, S. J. Journal of Power Sources 2015, 299, 221.

(4) Loeffler, N.; von Zamory, J.; Laszczynski, N.; Doberdo, I.; Kim, G.-T.; Passerini, S. Journal of Power Sources 2014, 248, 915.

(5) Doberdò, I.; Löffler, N.; Laszczynski, N.; Cericola, D.; Penazzi, N.; Bodoardo, S.; Kim, G.T.; Passerini, S. Journal of Power Sources 2014, 248, 1000.

(6) ÇEtinel, F.; Bauer, W. Bull Mater Sci 2014, 37, 1685.

(7) Li, J.; Armstrong, B.; Kiggans, J.; Daniel, C.; Wood III, D. Langmuir 2012, 28, 3783.

(8) Li, J.; Klöpsch, R.; Nowak, S.; Kunze, M.; Winter, M.; Passerini, S. Journal of Power Sources 2011, 196, 7687. 
(9) Zhong, H.; Sun, M.; Li, Y.; He, J.; Yang, J.; Zhang, L. Journal of Solid State Electrochemistry 2015, 1.

(10) Li, J.; Armstrong, B. L.; Daniel, C.; Kiggans, J.; Wood Iii, D. L. Journal of Colloid and Interface Science 2013, 405, 118.

(11) Guerfi, A.; Kaneko, M.; Petitclerc, M.; Mori, M.; Zaghib, K. Journal of Power Sources 2007, 163, 1047.

(12) Li, C. C.; Lee, J. T.; Peng, X. W. Journal of the Electrochemical Society 2006, 153, A809.

(13) Lee, J.-T.; Chu, Y.-J.; Peng, X.-W.; Wang, F.-M.; Yang, C.-R.; Li, C.-C. Journal of Power Sources 2007, 173, 985.

(14) Wu, Q.; Ha, S.; Prakash, J.; Dees, D. W.; Lu, W. Electrochimica Acta 2013, 114, 1.

(15) Li, C.-C.; Wang, Y.-W. Journal of Power Sources 2013, 227, 204.

(16) Fergus, J. W. Journal of Power Sources 2010, 195, 939.

(17) Loeffler, N.; Kopel, T.; Kim, G.-T.; Passerini, S. Journal of the Electrochemical Society 2015, 162, A2692.

(18) Li, C. C.; Peng, X. W.; Lee, J. T.; Wang, F. M. Journal of the Electrochemical Society 2010, 157, A517.

(19) Porcher, W.; Lestriez, B.; Jouanneau, S.; Guyomard, D. Journal of Power Sources 2010, $195,2835$.

(20) Li, J.; Armstrong, B. L.; Kiggans, J.; Daniel, C.; Wood, D. L. Journal of the Electrochemical Society 2013, 160, A201.

(21) Li, J.; Rulison, C.; Kiggans, J.; Daniel, C.; Wood III, D. L. J. Electrochem. Soc. 2012, 159, A1152.

(22) Zhang, X.; Jiang, W. J.; Zhu, X. P.; Mauger, A.; Qilu; Julien, C. M. Journal of Power Sources 2011, 196, 5102.

(23) Zaghib, K.; Dontigny, M.; Charest, P.; Labrecque, J. F.; Guerfi, A.; Kopec, M.; Mauger, A.; Gendron, F.; Julien, C. M. Journal of Power Sources 2008, 185, 698.

(24) Burrell, A. K., "Enabling High-Energy/Voltage Lithium-Ion Cells for Transportation Applications," DOE Annual Merit Review, Crystal City, VA, June 8-12, 2015.

(25) C. Daniel, and Mike Wixom, "Transformational electrode drying process", ORNL/TM2012/617, DOI:10.2172/1060885 